\title{
Exposure to revised drinking guidelines and 'COM-B' determinants of behaviour change: descriptive analysis of a monthly cross-sectional survey in England
}

Abigail K. Stevely ${ }^{1 *}$ (D, Penny Buykx ${ }^{2,3}$, Jamie Brown ${ }^{3,4,5}$, Emma Beard $^{3,4,5}$, Susan Michie ${ }^{5}$, Petra S. Meier ${ }^{2,3}$ and John Holmes ${ }^{2,3}$

\begin{abstract}
Background: January 2016 saw the publication of proposed revisions to the UK's lower risk drinking guidelines but no sustained promotional activity. This paper aims to explore the impact of publishing guidelines without sustained promotional activity on reported guideline exposure and determinants of behaviour (capability, opportunity and motivation) proposed by the COM-B model.

Methods: Data were collected by a monthly repeat cross-sectional survey of adults (18+) resident in England over 15 months between November 2015 and January 2017 from a total of 16,779 drinkers, as part of the Alcohol Toolkit Study. Trends and associated 95\% confidence intervals were described in the proportion of reported exposure to guidelines in the past month and measures of the capability, opportunity and motivation to consume alcohol within drinking guidelines.

Results: There was a rise in reported exposure to drinking guidelines in January 2016 (57.6-80.6\%) which did not reoccur in January 2017. Following the increase in January 2016, reported exposure reduced slowly but remained significantly higher than in December 2015. In February 2016, there was an increase in measures of capability (31. $1 \%$ reported tracking units of alcohol consumption and $87.8 \%$ considered it easier to drink safely) and opportunity (84.0\% perceived their lifestyle as conducive to drinking within guidelines). This change was not maintained in subsequent months. Other measures showed marginal changes between January and February 2016 with no evidence of change in subsequent months.
\end{abstract}

Conclusions: Following the publication of revised drinking guideline in January 2016, there was a transient increase in exposure to guidelines, and capability and opportunity to drink within the guidelines that diminished over time. The transience and size of the changes indicate that behaviour change is unlikely. Well-designed, theory-based promotional campaigns may be required for drinking guidelines to be an effective public health intervention.

Keywords: Drinking guidelines, Health promotion, Evaluation, Alcohol consumption, Trend analysis

* Correspondence: Astevely1@sheffield.ac.uk

${ }^{1}$ School of Health and Related Research, University of Sheffield, Sheffield, UK

Full list of author information is available at the end of the article 


\section{Background}

\section{Drinking guidelines and behaviour change}

In 2012, as part of the UK Government's Alcohol Strategy, the country's Chief Medical Officers were asked to oversee a review of their lower risk drinking guidelines. The review aimed to "support individuals to make informed choices about healthier and responsible drinking" (p. 4). Key milestones in the process of updating the guidelines are summarised in Table 1. Two expert groups considered whether the guidelines should be updated and were persuaded by new high quality evidence, particularly relating to reduced certainty about cardio-protective effects from moderate drinking and increased certainty about risk of cancer. January 2016 saw the publication of proposed revisions to the drinking guidelines (DGs) which recommended that "To keep health risks from alcohol to a low level it is safest not to drink more than 14 units a week on a regular basis. If you regularly drink as much as 14 units per week, it is best to spread your drinking evenly over 3 or more days". These were the first revisions since the previous guidelines were published in 1995. The weekly consumption guidance for men was reduced by approximately a third and the focus shifted from daily to weekly limits [1]. In the UK, a unit is $8 \mathrm{~g}$ of pure ethanol and so the guideline figure of 14 units per week is equivalent to $112 \mathrm{~g}$ of ethanol [2]. It is common for guidelines to provide separate recommendations for men and women, with weekly guidelines ranging from 60 to $190 \mathrm{~g}$ of ethanol for women and 70-288 $\mathrm{g}$ for men [3-5]. The Guidelines Development Group considered the evidence on the risk of alcohol-related harm faced by men and women and concluded that a single low risk guideline figure was justified because risks were similar at moderate consumption levels [2].

After publishing the proposed revisions in January, the new guidelines were subject to a public consultation until April 2016 which focused on whether the recommendations and reasoning behind them were clear and easy to understand $[2,6]$. The final guidelines were released in August 2016 after only minor changes to wording. Although

Table 1 Key milestones in updating UK lower risk drinking guidelines (2012-2016)

\begin{tabular}{|c|c|}
\hline Milestone & Date \\
\hline Review of lower risk drinking guidelines announced & March 2012 \\
\hline $\begin{array}{l}\text { Expert group assessment of the need to update the } \\
\text { guidelines }\end{array}$ & $2013-2014$ \\
\hline $\begin{array}{l}\text { Guidelines development group considered the evidence } \\
\text { and produced advice on revisions to the guidelines }\end{array}$ & 2014-2015 \\
\hline Publication of proposed revisions & January 2016 \\
\hline $\begin{array}{l}\text { Public consultation on the clarity of the guidelines } \\
\text { concluded }\end{array}$ & April 2016 \\
\hline Final guidelines released & August 2016 \\
\hline
\end{tabular}

there was minimal UK Government publicity in August, publication of the draft guidelines in January 2016 was accompanied by press releases and other prominent media activity from not only the UK Government, but also a range of other interest groups.

Guidelines, and their promotion, are prominent features of public health policy in the UK and beyond with governments or medical authorities publishing drinking guidelines in at least 37 countries [3]. However, international evidence for their effectiveness in reducing alcohol consumption is limited. There are a lack of high quality evaluations of the effects of promotional efforts and a literature review concluded that very little research has been conducted into their use for primary prevention [7]; although the available evidence generally indicates a lack of impact [8]. One limitation of previous work in this area is that it does not explore different stages or components of behaviour change from receipt of the information through to an actual shift in behaviour, and so the areas in which DG publication and promotion fails are not clear in the context of well-established theoretical frameworks. A detailed understanding of potential impacts of DGs on the determinants of behaviour change is important in order to consider methods to improve effectiveness.

\section{Behaviour change model}

There are a number of theoretical frameworks available to understand processes of behaviour change and the model used was chosen as it integrates core constructs present in many earlier theories [9]. The model specifies that capability, opportunity and motivation interact as a system to generate behaviour ('COM-B' model). Capability is considered as being physical or psychological, opportunity as environmental or social, and motivation as automatic or reflective. In the context of drinking within guidelines, examples of capability would include knowledge of safe drinking, skills to track units and selfefficacy to drink within guidelines; opportunity would include suitability of lifestyle and access to information about cutting down; and motivation would include attempts, intention and desire to drink within guidelines. Prior evidence suggests that the publication and promotion of drinking guidelines can produce improvements in knowledge, as well as that guideline interventions are effective in changing reflective motivation [9]. However, evidence of effects of publishing or promoting drinking guidelines on other components of the COM-B model is lacking [10-12].

\section{Application of the COM-B model to drinking guidelines}

This research aims to explore whether drinkers were exposed to the revised guidelines following their publication and promotion in January 2016 and whether capability, 
opportunity and motivation to drink within the revised guidelines changed.

\section{Methods \\ Data}

Data for this study were taken from the Alcohol Toolkit Study (ATS) which is a monthly repeat cross-sectional survey of approximately 1600 adults living in England. Data collected between November 2015 and January 2017 were included to provide a total sample size of 25,443 . This timeframe includes two survey waves prior to the revised guideline publication and 13 subsequent waves. Data collection for January 2016 occurred in the week following publication of the proposed DGs. Since the Alcohol Toolkit Study was expanded for the purpose of evaluating the new low impact DGs in November 2015, data collection prior to this was not possible.

The ATS uses a type of random location sampling in which 171,356 'output areas', each of which holds around 300 households, are stratified based on geographic area and socioeconomic status. Sampled strata are then randomly allocated to interviewers who choose the houses to visit and conduct computer-assisted interviews with one member of each household. This process continues until quota targets, based on factors which influence the probability of being at home, are met. Data are then weighted using an iterative sequence of weighting adjustments to match nationally representative profiles based on age, sex, social-grade, region, working status and children in the household. The sampling method used is often considered to be superior to standard quota sampling as the choice of properties approached is significantly reduced. As interviewers choose houses within their allocated strata, there is no definite gross sample size and response/refusal rates cannot be meaningfully calculated. The full ATS methods are described in the study protocol [13].

The first question of the AUDIT (Alcohol Use Disorders Identification Test) screening tool [14] was used to assess the drinking status of respondents. All survey participants were asked 'How often do you have a drink containing alcohol?' and those who responded 'Never' were classified as nondrinkers and excluded from analyses (9177 participants).

\section{Measures}

\section{Drinking guideline exposure}

Respondents who reported that they were drinkers were asked: "Before this interview, have you ever heard of there being a recommended maximum number of alcohol units people should drink in a day or a week? This is sometimes known as a 'drinking guideline'." The response options were "Yes" or "No". Those responding "No" were classified as "unexposed' to the DGs while those responding "Yes" were asked: "In which of the following places, if any, have you seen, read or heard this drinking guideline figure mentioned in the last month?". There were 12 possible responses to this question including the option "Have not seen it mentioned in any of these places". Those responding that they had not seen it were also classified as 'unexposed' and those providing one or more place(s) that they had seen the guideline were classified as 'exposed'.

\section{COM-B determinants of behaviour}

The main outcome measures were 10 questions with ordinal response scales designed to capture the capability, opportunity and motivation components of the COM-B model (Table 2). The design of these questions was influenced by questions which were found to effectively predict smoking behaviour in the Smoking Toolkit Study (STS) [15].

Responses to these questions have been dichotomised into 'positive' and 'negative' groups as shown in Table 2 with either two (for five item scales) or three (for seven item scales) response categories falling into the positive group. The exception to this is Item 1 (Table 2), which asks how many units of alcohol can be regularly consumed in a day without significantly harming health, where the first two responses ( 1 unit, 2 units) have been selected as positive as this is consistent with the new lower risk DGs.

\section{Analysis}

Changes in responses to 10 COM-B measures over the 15 monthly datasets between November 2015 and January 2017 were examined using the 95\% confidence intervals around the overall proportion of positive responses. December 2015 was used as a reference point to identify trends, since the draft guidelines were published in January 2016. All analyses were based on weighted survey data. Cases were excluded pairwise where the response to the question being analysed was 'Don't know', 'Refused' or missing. The number of exclusions was highest for the first question, which related to knowledge of how many units it is safe to regularly consume $(n=1443)$. The number excluded for the rest of the measures was between 243 and 191. The same approach was used to assess change in reported DG exposure for which 2131 participants were excluded due to missing data on their exposure status.

To explore whether the method of dichotomising the COM-B measures affected results, sensitivity analyses were undertaken where five-point scales contained only one positive result (instead of two) and seven point scales contained only two positive responses (instead of three). A further sensitivity analysis was conducted for item 1, in which participants who responded 'Don't 
Table 2 Survey questions and response options

\begin{tabular}{|c|c|c|}
\hline COM-B dimension & Response option & $\begin{array}{l}\text { Total missing, 'don't know' or } \\
\text { 'refused' }\end{array}$ \\
\hline \multicolumn{3}{|l|}{ Capability } \\
\hline \multicolumn{3}{|l|}{ Knowledge } \\
\hline $\begin{array}{l}\text { Item 1: What do you think is the most number of units you can } \\
\text { personally drink in a day on a regular basis before it does } \\
\text { significant harm to your health? }\end{array}$ & $1^{a}-7+$ units & $1358(8.1 \%)$ \\
\hline \multicolumn{3}{|l|}{ Perceived capability } \\
\hline $\begin{array}{l}\text { Item 2: How easy or difficult do you personally find it to drink three } \\
\text { or fewer units of alcohol a day? }\end{array}$ & 1. Extremely difficult -7 . Extremely easy ${ }^{a}$ & $141(0.8 \%)$ \\
\hline \multicolumn{3}{|l|}{ Skills } \\
\hline $\begin{array}{l}\text { Item 3: How often, if at all, do you keep track of how many units of } \\
\text { alcohol you personally drink each week? }\end{array}$ & 1. Never - 7. Always ${ }^{a}$ & $91(0.5 \%)$ \\
\hline \multicolumn{3}{|l|}{ Opportunity } \\
\hline \multicolumn{3}{|l|}{ Social opportunity } \\
\hline $\begin{array}{l}\text { Item 4: How easy or difficult do you think your lifestyle makes it for } \\
\text { you to personally drink three or fewer units of alcohol a day? }\end{array}$ & 1. Extremely difficult -7 . Extremely easy ${ }^{a}$ & $184(1.1 \%)$ \\
\hline $\begin{array}{l}\text { Item 5: Do you know where to go if you wanted advice or } \\
\text { information on how to cut down on your drinking of alcoholic } \\
\text { drinks? }\end{array}$ & 1. I have no idea -5 . Yes, definitely ${ }^{a}$ & $112(0.7 \%)$ \\
\hline \multicolumn{3}{|l|}{ Motivation } \\
\hline \multicolumn{3}{|l|}{ Reflective motivation } \\
\hline $\begin{array}{l}\text { Item 7: To what extent are you actively trying to avoid drinking } \\
\text { more alcohol than is good for you? }\end{array}$ & 1. Not at all -5 . Definitely ${ }^{a}$ & $116(0.7 \%)$ \\
\hline $\begin{array}{l}\text { Item 9: To what extent do you intend to keep your drinking within } \\
\text { safe limits? }\end{array}$ & 1. Not at all -5 . Definitely ${ }^{a}$ & $110(0.7 \%)$ \\
\hline \multicolumn{3}{|l|}{ Automatic motivation } \\
\hline $\begin{array}{l}\text { Item 6: To what extent do you want to avoid drinking more than is } \\
\text { good for you rather than just thinking that you should? }\end{array}$ & 1. Not at all - 5. Definitely ${ }^{a}$ & $234(1.4 \%)$ \\
\hline $\begin{array}{l}\text { Item 8: To what extent do you want to keep your drinking within } \\
\text { safe limits? }\end{array}$ & 1. Not at all -5 . Definitely ${ }^{a}$ & $108(0.6 \%)$ \\
\hline $\begin{array}{l}\text { Item 10: Nowadays how concerned, if at all, are you about drinking } \\
\text { more units of alcohol than is good for you? }\end{array}$ & $\begin{array}{l}\text { 1. Not at all concerned - 5. Definitely } \\
\text { concerned }^{a}\end{array}$ & $94(0.6 \%)$ \\
\hline
\end{tabular}

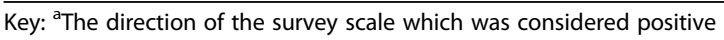

know' were included in the negative response group. All analyses were conducted in IBM SPSS Statistics version 23 .

\section{Results}

\section{Drinking guideline exposure}

Drinkers' self-reported exposure to DGs in any location rose from $57.7 \%$ in December 2015 to $80.6 \%$ in January 2016 (see Fig. 1). Figure 1 shows the trend in reported exposure with $95 \%$ confidence intervals. Subsequent to January 2016 this has gradually decreased but remained higher than in December 2015. Monthly trends, and associated 95\% confidence intervals, are available for all measures (see Additional file 1).

\section{Responses to capability measures}

Among drinkers, $34.0 \%$ (31.5-37.2\%) said that it was safe to regularly drink two or fewer units in December 2015. There was no clear trend in this proportion over time. The proportion of people who believed it was easy to drink less than three units a day and who tracked their units increased in February 2016 when compared with December 2015, although these improvements were modest (4.4 and 5.8\%) and not maintained in the subsequent months (see Fig. 2).

\section{Responses to opportunity measures}

In order to measure social opportunity factors, participants were asked how difficult their lifestyle makes it to drink three or fewer units per day. Responses to this measure also improved from December 2015 to February 2016: the proportion who reported that their lifestyle made it easy to drink three or fewer units per day rose from $77.9 \%$ (75.5-80.4\%) to $84.0 \%(81.8-86.2 \%)$ but the improvement was also not maintained.

The second opportunity measure asked whether the respondent knew where to find information on cutting 


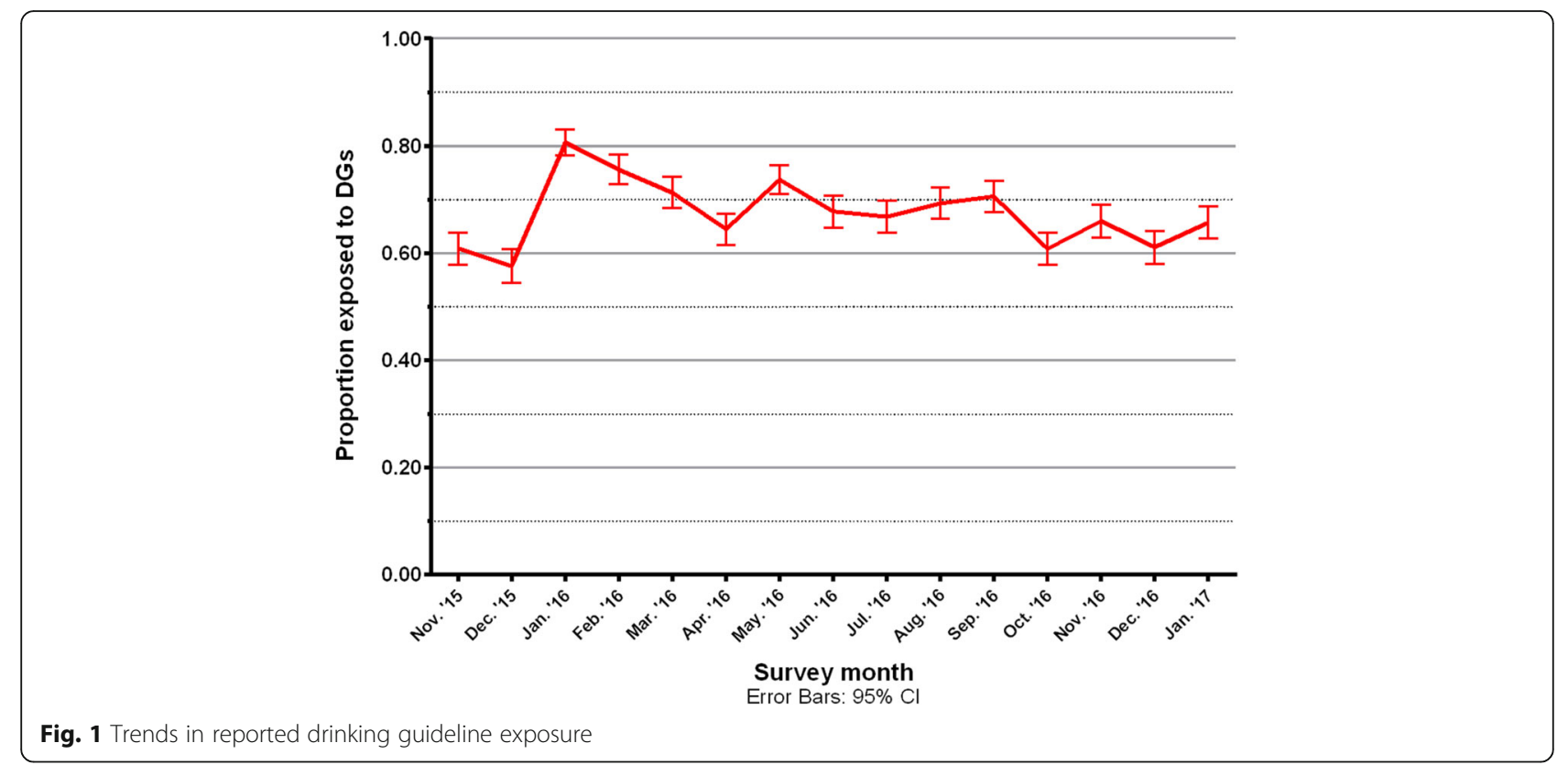

down their consumption of alcohol. There was no clear trend over time in positive responses to this (see Fig. 3).

\section{Responses to motivation measures}

The first four questions designed to measure motivation (six, seven, eight and nine) focus on different aspects of motivation. The first two ask about drinking more than is good for you, whether the respondent 'want/s to' avoid it and whether they're 'actively' trying to avoid it. The next pair relate to respondents keeping their drinking within safe limits and respectively ask whether they 'want to' or 'intend to' do so. The questions which ask about whether participants 'want to' engage in the specified behaviour are designed to assess automatic motivation while their counterparts assess reflective motivation.

The proportions of respondents who reported that they wanted to, or were actively trying to avoid drinking more than is good for them in December 2015 were lower (52.2 and 42.5\%) than the proportions of people who wanted to, or intended to, keep their drinking within safe limits (77.0 and $77.0 \%)$. Trends in positive responses to these four measures were marginal between December and February.

Lastly, automatic motivation was further assessed by question ten, which asked how concerned each respondent was about drinking more than is good for them. In December 2015 this proportion was 25.0\% (22.4-27.6\%). There was no clear change in the proportion of respondents

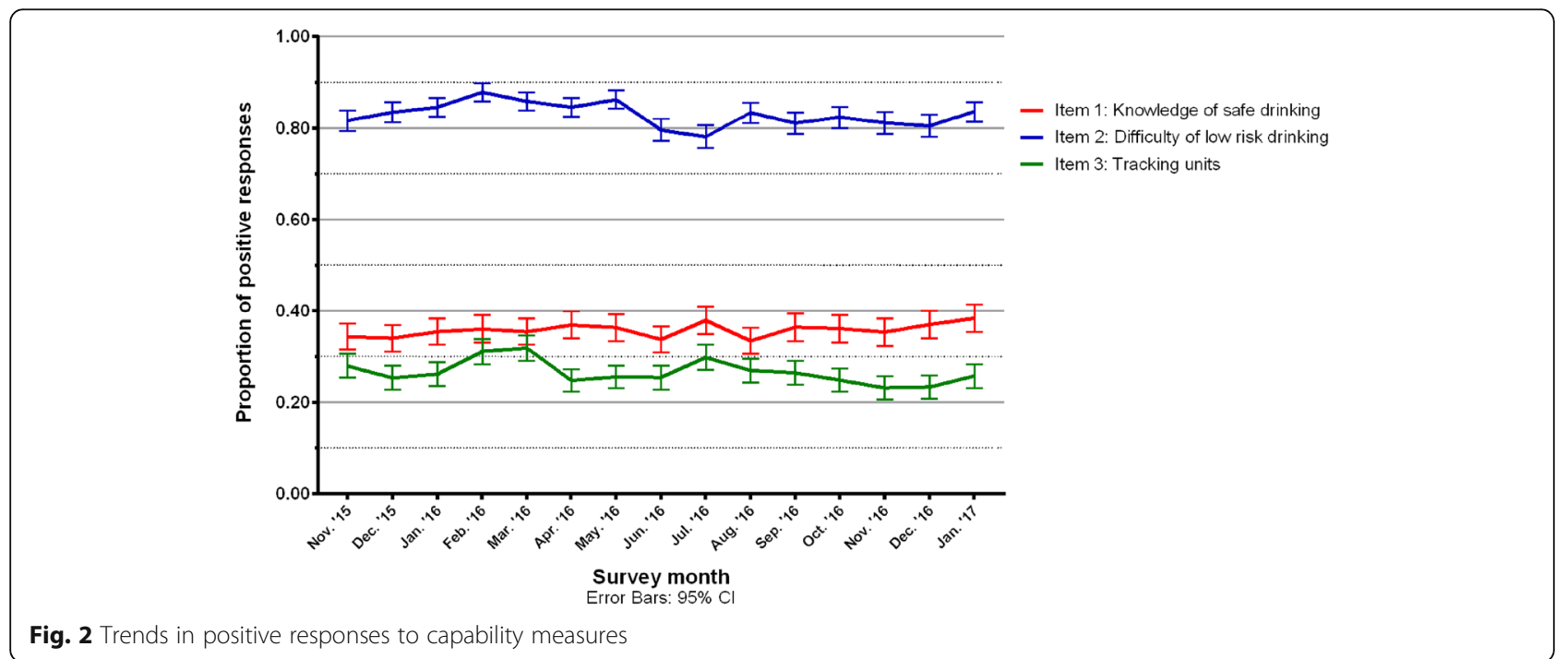




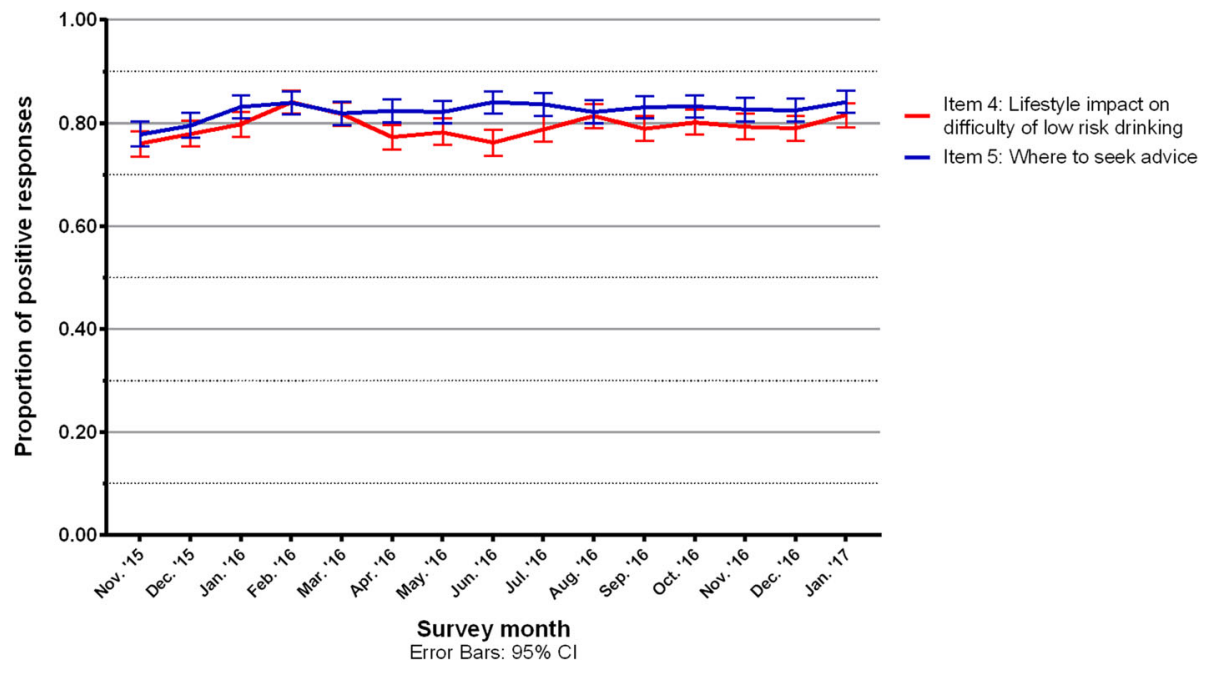

Fig. 3 Trends in positive responses to opportunity measures

who were concerned over time (see Fig. 4). Sensitivity analyses for each of the ten COM-B measures did not significantly change the results.

\section{Discussion}

We found that there was an increase in reported exposure to drinking guidelines in January 2016, which did not reoccur in January 2017. Following this, reported exposure fell, although remaining significantly higher than in December 2015. Following this rise in exposure, we found increases in measures of capability (proportion who reported tracking units of alcohol consumption and considered it easier to drink safely) and opportunity (proportion who perceived their lifestyle as conducive to drinking within guidelines). However, the change did not persist over subsequent months. Additionally, we observed some marginal changes in other measures.
A key strength of this research is its use of a theory-based framework for studying behaviour change (COM-B) in order to explore the short term effects of promoting lower risk DG [9]. Further strengths include those of the Alcohol Toolkit Study, which collects a nationallyrepresentative sample of drinkers living in private households in England using consistent methods on a monthly basis which enabled analysis of pre- and postintervention trends across multiple data points [13]. The relative robustness of the methods compared to previous studies and the theoretically informed approach are likely to strengthen the generalisability of the results to culturally-similar high income countries.

Among the key limitations are the potential confounding effects of December and January being traditionally heavy and light drinking months. However, data were collected over 15 months which facilitated comparison of results at

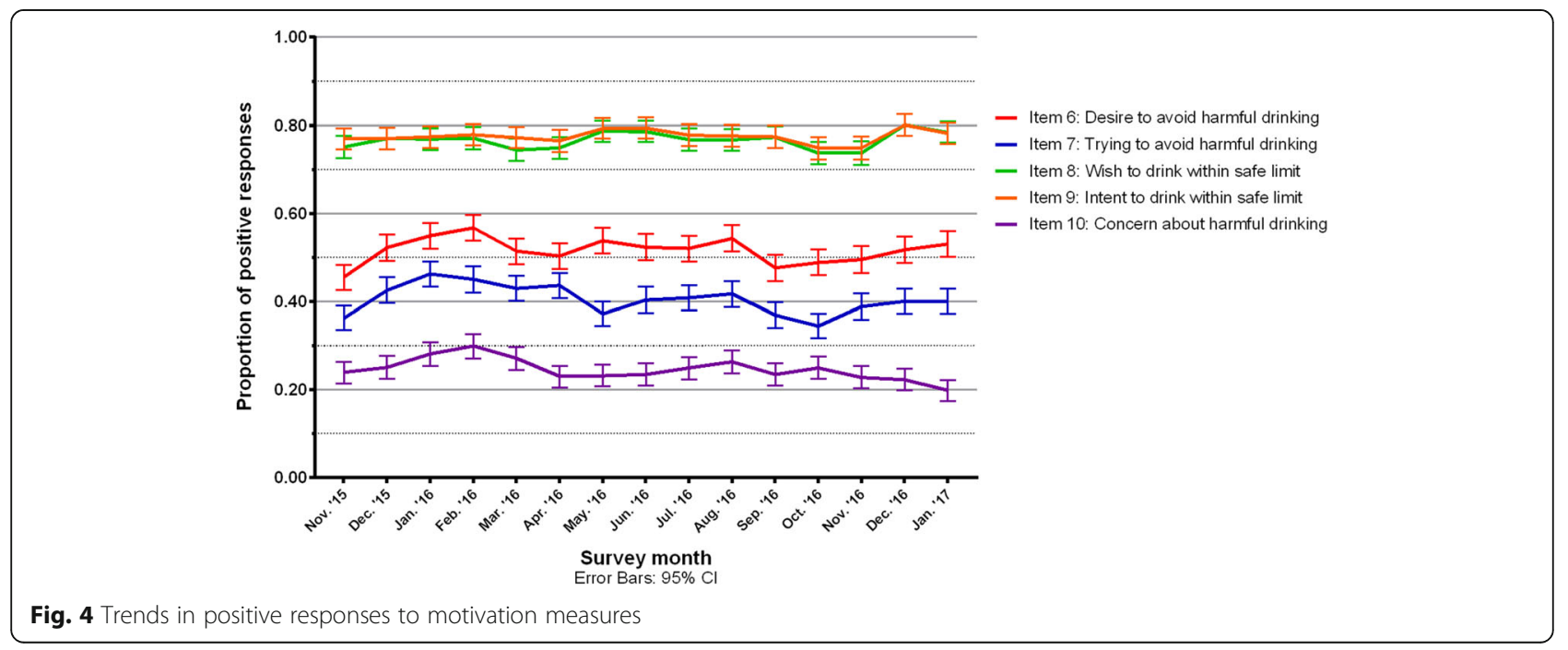


guideline publication to those from the following year. Data collection was by self-report which is subject to known biases in studies on alcohol consumption; even though this study is not measuring consumption directly, issues such as social desirability may still have impacted responses [16, 17]. Since the results presented aggregate the responses of all participants, conclusions regarding the effect of publication of the new lower risk DGs on population subgroups cannot be made. The question wording did not explicitly refer to the UK official government guidelines but we are unaware of other advice being widely interpreted as guidelines. Lastly, the proportion of non-drinkers in the ATS sample appears somewhat higher than other surveys in England: for example, the Adult Psychiatric Morbidity Survey (APMS) - which is the only other survey in England to also include the AUDIT - reported that 23\% of respondents did not drink at all, while the equivalent figure for the ATS in 2014 was 29\% [18]. Unlike the APMS, however, the ATS does not include a clarifying question and likely misclassifies a proportion of people who drink very rarely as 'never' [19].

Although previous evaluation of the efficacy of drinking guidelines to change behaviour is limited, this result is consistent with findings of low impact on those measures which have been explored [7, 8]. A contributing factor in this study may be the lack of large-scale organised promotion of the new low-risk DGs. For example, there have been no national mass media campaigns following the initial announcement of the guidelines and, despite over $80 \%$ of UK alcoholic product labels including the DGs [20], these labels have not been updated to give the new recommendations with guidance on how to do so only being published in March 2017 [21]. Additionally, reviews of the effectiveness of behaviour change efforts have consistently shown that achieving exposure is not sufficient to achieve effectiveness where interventions and campaigns are poorly designed. Promotion of drinking guidelines should therefore be designed with reference to prior theory and evidence on effective communication of messages and techniques for changing behaviours $[22,23]$. This could be supported by the finding of this research that although reported exposure to drinking guidelines increased in January 2016 and remained above the level observed in December 2015, sustained change in the theoretical mediators of behaviour change was not demonstrated.

There was no difference in respondents' knowledge of the number of units per day which it is safe to drink regularly over time (see Additional file 1). This could be seen as inconsistent with existing literature, which suggests that DGs can improve public knowledge of alcohol harms [10-12, 24]. Furthermore, the percentage of people who gave one or two units as the most units they could regularly drink on a single day before doing significant harm to their health was low in January 2016
(35.4\%), meaning that most people thought that the level for low risk drinking was above that given in the new low-risk DGs. However, the measure of knowledge used here does not ask what the guideline figure is - rather it asks for the number of units that the respondent can regularly drink without significant health risk. It may be that this is interpreted as being different to the low-risk DG. Additionally, the number of units that it is safe to drink 'regularly' according to the low risk DGs is open to interpretation. It was not within the scope of this study to explore lay interpretations of the new guidelines or the COM-B measures used.

Given the results presented here, and the findings of low impact of DGs on alcohol consumption in the previous literature $[7,8]$, policy makers should consider the process of guideline implementation as well as additional or alternative methods to DGs when working to produce change in alcohol consumption. It is important to provide accurate information on the risks of alcohol consumption [4]. However, guidelines do not implement themselves; they require active, evidence-based strategies to support implementation $[25,26]$. Furthermore, in order to build on the current findings, it is important to consider the impact of drinking guidelines on higher risk drinkers, who may view 14 units per week as unobtainable, and on health inequalities given the stark differences in risk faced by those in different socioeconomic groups [27-29].

\section{Conclusions}

The publication and promotion of new low-risk drinking guidelines in January 2016 did not result in persistent improvements in UK adults' capability, opportunity and motivation to reduce their alcohol consumption, despite an increase in reported drinking guideline exposure. Evaluations of well-designed, theory-based promotional campaigns are required to build the evidence about how to enable drinking guidelines to be an effective public health intervention.

\section{Endnotes}

${ }^{1}$ The previous guidelines (1995) recommended that men should not regularly consume more than 3-4 units a day and 2-3 units a day for women. The definition of regularly was every day or nearly every day.

\section{Additional file}

Additional file 1: Trends in reported drinking guideline exposure and responses to COM-B measures. (DOCX $26 \mathrm{~kb}$ )

\section{Abbreviations}

ATS: Alcohol Toolkit Study; AUDIT: Alcohol Use Disorders Identification Test; COM-B: Stands for: capability, opportunity, motivation and behaviour; DG: Drinking guideline; STS: Smoking Toolkit Study 


\section{Acknowledgements}

We are grateful to Robert West and Sarah Lewis for their contributions to the development and design of the survey questions used in this study and to other members of the Alcohol Toolkit Study research team who contributed to the wider development of the data. We would like to thank Norman Giesbrecht and Timothy S. Naimi for their comments on an earlier draft of this manuscript during peer review.

\section{Funding}

This work was funded by the National Institute for Health Research (NIHR) Public Health Research (PHR) Programme (Project Number: 15/63/01). The views and opinions expressed are those of the authors and do not necessarily reflect those of the PHR Programme, NIHR or the Department of Health. Additional data collection was funded by the NIHR School for Public Health Research which also contributed funding for $\mathrm{JH}$ and PB. JB is funded by CRUK (C1417/A22962).

\section{Availability of data and materials}

The datasets during and/or analysed during the current study available from the corresponding author on reasonable request.

\section{Authors' contributions}

Developed the COM-B measures: SM, JH. Commented during COM-B measure development: JB, PM, PB, EB. Conceived and designed the analyses: JH, AS. Performed the analyses: AS. Wrote the manuscript: AS, PB, JH. All authors have commented on and approved the final manuscript.

\section{Ethics approval and consent to participate}

Informed consent is given verbally by ATS participants after interviewers explain the study and give assurance that it is being conducted in line with the Market Research Society Code of Conduct. Ethical approval for the wider Alcohol Toolkit Study and for this evaluation of the UK lower risk drinking guidelines were granted by the University College London ethics committee and the University of Sheffield ethics committee respectively.

\section{Consent for publication}

Not applicable.

\section{Competing interests}

AKS: Has no competing interests to declare.

PB: Was commissioned by Public Health England to provide an epidemiological modelling report which informed development of the new UK lower risk drinking guidelines.

JB: Has received unrestricted research funding from Pfizer for studies relating to smoking cessation.

SM: Has no competing interests to declare.

PM: Was advisor to (and previous member of) the UK Chief Medical Officers' Guidelines Development Group and was commissioned by Public Health England to provide an epidemiological modelling report which informed development of the new UK lower risk drinking guidelines.

$J \mathrm{H}$ : Was advisor to (and previous member of) the UK Chief Medical Officers' Guidelines Development Group and was commissioned by Public Health England to provide an epidemiological modelling report which informed development of the new UK lower risk drinking guidelines.

\section{Publisher's Note}

Springer Nature remains neutral with regard to jurisdictional claims in published maps and institutional affiliations.

\footnotetext{
Author details

'School of Health and Related Research, University of Sheffield, Sheffield, UK. ${ }^{2}$ Sheffield Alcohol Research Group, School of Health and Related Research (ScHARR), University of Sheffield, Sheffield, UK. ${ }^{3}$ UK Centre for Tobacco and Alcohol Studies (UKCTAS), Nottingham, UK. ${ }^{4}$ Department of Behavioural Science and Health, University College London, London, UK. ${ }^{5}$ Department of Clinical, Educational and Health Psychology, University College London, London, UK.
}

Received: 6 July 2017 Accepted: 30 January 2018

Published online: 14 February 2018

\section{References}

1. HM Government. The Government's Alcohol Strategy. 2012. https://www. gov.uk/government/publications/alcohol-strategy. Accessed 25 May 2017.

2. Department of Health. Alcohol Guidelines Review - Report from the Guidelines development group to the UK Chief Medical Officers. HM Government. 2016. https://www.gov.uk/government/consultations/ health-risks-from-alcohol-new-guidelines. Accessed 25 May 2017.

3. Kalinowski A, Humphreys K. Governmental standard drink definitions and low-risk alcohol consumption guidelines in 37 countries. Addiction. 2016; https://doi.org/10.1111/add.13341.

4. Broholm K, Galluzzo L, Gandin C, Ghirini S, Ghiselli A, Jones L, Martire S, Mongan D, Montonen M, Mäkelä P, et al. Good practice principles for low risk drinking guidelines. 2016. http://www.tai.ee/images/WP5_Good_ practice_low_risk_guidelines.pdf. Accessed 4 Dec 2017.

5. Scafato E, Galluzzo L, Ghirini S, Gandin C, Martire S. Low risk drinking guidelines in Europe: overview of RARHA survey results. 2016. http://www rarha.eu/Resources/Guidelines/Documents/Overview\%20WP5 T1\%20LowRiskDrinkingGuidelines_FINAL.pdf. Accessed 4 Dec 2017.

6. HM Government. Health risks from alcohol: new guidelines. 2016. https:// www.gov.uk/government/consultations/health-risks-from-alcohol-newguidelines. Accessed 25 May 2017.

7. Walsh GW, Bondy SJ, Rehm J. Review of Canadian low-risk drinking guidelines and their effectiveness. Can J Public Health. 1998:89(4):241-7.

8. Babor TF, Caetano R, Casswell S, Edwards G, Giesbrecht N, Graham K, Grube J, Hill L, Holder H, Homel R, et al. Alcohol: no ordinary commodity: research and public policy. 2nd ed. Oxford: Oxford University Press; 2010.

9. Michie $S$, van Stralen MM, West R. The behaviour change wheel: a new method for characterising and designing behaviour change interventions. Implement Sci. 2011;6(1):42.

10. Grønbæk M, Strøger U, Strunge H, Møller L, Graff V, Iversen L. Impact of a 10-year nation-wide alcohol campaign on knowledge of sensible drinking limits in Denmark. Eur J Epidemiol. 2001;17(5):423-7.

11. Livingston M. Perceptions of low-risk drinking levels among Australians during a period of change in the offical drinking guidelines. Drug Alcohol Rev. 2012; https://doi.org/10.1111/j.1465-3362.2011.00414.x.

12. Strunge $\mathrm{H}$. Danish experiences of national campaigns on alcohol 1990-1996. Drugs Educ Prev Policy. 1998;5(1):73-9.

13. Beard E, Brown J, West R, Acton C, Brennan A, Drummond C, Hickman M, Holmes J, Kaner E, Lock K, et al. Protocol for a national monthly survey of alcohol use in England with 6-month follow-up: The Alcohol Toolkit Study'. BMC Public Health. 2015:15:230.

14. Babor TF, Higgins-Biddle JC, Saunders JB, Monteiro MG. AUDIT: the alcohol use disorders identification test: guidelines for use in primary care. 2nd ed. Geneva: World Health Organisation; 2001.

15. Fidler JA, Shahab L, West O, Jarvis MJ, McEwen A, Stapleton JA, Vangeli E, West R. 'The smoking toolkit study': a national study of smoking and smoking cessation in England. BMC Public Health. 2011;11(1):479.

16. Gmel G, Graham K, Kuendig H, Kuntsche S. Measuring alcohol consumption - should the 'graduated frequency' approach become the norm in survey research? Addiction. 2006;101(1):16-30.

17. Podsakoff PM, MacKenzie SB, Lee JY. Common method biases in behavioral research: a critical review of the literature and recommended remedies. J Appl Psychol. 2003;88(5):879-903.

18. McManus $S$, Bebbington $P$, Jenkins $R$, Brugha T, editors. Mental health and wellbeing in England: adult psychiatric morbidity survey 2014. Leeds: NHS Digital; 2016.

19. Fuller E. Health Survey for England, 2014: Chapter 8: Adult Alcohol Consumption. 2014. http://content.digital.nhs.uk/catalogue/PUB19295. Accessed 8 Dec 2017

20. Campden BRI. Final report on: audit of compliance of alcohol beverage labels available from the off-trade with the Public Health Responsibility Deal Labelling Pledge. 2014. https://responsibilitydeal.dh.gov.uk/wp-content/ uploads/2014/11/Campden-BRI_Audit-of-PHRD-labelling-compliance-2014-_ FINAL-report_October2014-final.pdf. Accessed 25 May 2017.

21. Department of Health. Communicating the UK Chief Medical Officers' alcohol guidelines. HM Government. 2017. https://www.gov.uk/ government/publications/communicating-the-uk-chief-medical-officersalcohol-guidelines. Accessed 25 May 2017. 
22. Michie S, Johnston M, Francis J, Hardeman W, Eccles M. From theory to intervention: mapping theoretically derived behavioural determinants to behaviour change techniques. Appl Psychol. 2008;57(4):660-80.

23. Michie S, West R. Behaviour change theory and evidence: a presentation to government. Health Psychol Rev. 2013;7(1):1-22.

24. Holmes J, Brown J, Meier P, Beard E, Michie S, Buykx P. Short-term effects of announcing revised lower risk national drinking guidelines on related awareness and knowledge: a trend analysis of monthly survey data in England. BMJ Open. 2016;6(12):e013804. https://doi.org/10.1136/bmjopen2016-013804.

25. McKillop A, Crisp J, Walsh K. Practice guidelines need to address the 'how' and the 'what' of implementation. Prim Health Care Res Dev. 2011;13(1):48-59.

26. Shiffman RN, Dixon J, Brandt C, Essaihi A, Hsiao A, Michel G, O'Connell R. The GuideLine Implementability Appraisal (GLIA): development of an instrument to identify obstacles to guideline implementation. BMC Med Inform Decis Mak. 2005;5:23.

27. Smith K, Foster J. Alcohol, Health Inequalities and the Harm Paradox: Why some groups face greater problems despite consuming less alcohol. Institute of Alcohol Studies. 2014. http://www.ias.org.uk/uploads/pdf/AS\%20reports/ |AS\%20report\%20Alcohol\%20and\%20health\%20inequalities\%20FULL.pdf. Accessed 25 May 2017.

28. Baum F, Fisher M. Why behavioural health promotion endures despite its failure to reduce health inequities. Sociol Health IIIn. 2014;36(2):213-25.

29. Mäkelä P, Paljärvi T. Do consequences of a given pattern of drinking vary by socioeconomic status? A mortality and hospitalisation follow-up for alcoholrelated causes of the Finnish Drinking Habits Surveys. J Epidemiol Community Health. 2008;62(8):728-33.

\section{Submit your next manuscript to BioMed Central and we will help you at every step:}

- We accept pre-submission inquiries

- Our selector tool helps you to find the most relevant journal

- We provide round the clock customer support

- Convenient online submission

- Thorough peer review

- Inclusion in PubMed and all major indexing services

- Maximum visibility for your research

Submit your manuscript at www.biomedcentral.com/submit 